\title{
Nitrogen Oxides Emissions from a Diesel Engine Fuelled with Water-Diesel Microemulsions
}

\author{
Milena Górska ${ }^{1}$, Tomasz Skrzek²*
}

1 Faculty of Chemical Engineering and Material Science, Kazimierz Pulaski University of Technology and Humanities in Radom, Poland

2 Faculty of Mechanical Engineering, Kazimierz Pulaski University of Technology and Humanities in Radom, Poland

* Corresponding author's e-mail: t.skrzek@uthrad.pl

\begin{abstract}
In this study, an experiment was conducted to examine the AVL research diesel engine using two kinds of waterdiesel (W-D) fuel microemulsions. These W-D mixtures contained 3.5 and $7.0 \%$ by volume (\%, v/v) of distilled water dispersed in regular diesel fuel meeting the requirements of the EN590 standard. The engine was tested under the conditions of low, moderate and higher loads. This research was focused on the emission characteristics of nitrogen dioxide $\left(\mathrm{NO}_{2}\right)$ and nitrogen monoxide $(\mathrm{NO})$. Cumulative emission of $\mathrm{NO}_{\mathrm{x}}$ was also analyzed before being further discussed. The obtained results of this study showed that the addition of distilled water to the regular diesel fuel has a minor effect on the variation of the nitrogen oxides emission. It was confirmed that NO is the main component of $\mathrm{NO}_{\mathrm{x}}$ detected in the exhaust stream of the AVL engine fuelled with all tested fuels. It proves that the thermal mechanism of the nitrogen oxides formation was dominant in the combustion process. Moreover, it was found that the addition of water dispersed as microemulsion in diesel fuel had a minor effect on the reduction of the $\mathrm{NO}_{\mathrm{x}}$ emission.
\end{abstract}

Keywords: diesel engine; nitrogen oxides; fuel microemulsions.

\section{INTRODUCTION}

Internal combustion (IC) engines are considered to be the one of the most important sources of harmful gases emitted into the atmosphere. These pollutants have a negative impact not only on the human health but also are harmful for the animal and plant life. For this reason, the emissions of unburned hydrocarbons (HC), nitrogen oxides $\left(\mathrm{NO}_{\mathrm{X}}\right)$, carbon monoxide $(\mathrm{CO})$ and particulate matter (PM) are more and more limited by relevant legal regulations. In the case of the European Union (EU), these requirements are known as the Euro/EURO emission standards. These increasingly stricter limits of toxic gases emission stimulate the development of internal combustion (IC) engines. The process is supported by appropriate investigation for alternative and environmentally friendly fuels/biofuels too. For this reason, for many years scientists and researchers have focused on plant oils as a renewable source of energy for the engines. Additionally, alcohols such as methanol and ethanol as well as selected derivatives i.e. methyl tertiary butyl ether (MTBE) and ethyl tertiary butyl ether (ETBE) were investigated and used as a fuel additive for spark ignition and diesel engines $[9,10,30]$. Moreover, n-hexane was utilized in blend with canola oil as a fuel for diesel engines [20]. The combustion process of all these novel fuels helps reduce the emission of toxic gases. However, it must be additionally supported by the development of after-treatment systems such as diesel and gasoline particulate filters (DPF and GPF respectively), oxidation catalyst for diesels and three-way catalysts for gasoline engines. In the case of diesel engines, selective catalytic reduction (SCR) is also used for $\mathrm{NO}_{\mathrm{x}}$ reduction. It should be pointed that excessive 
emission of $\mathrm{NO}_{\mathrm{x}}$ is still a crucial problem of all diesel engines. For this reason, the diesel aftertreatment systems are still being developed in conjunction with the necessary research on novel fuels. An example of such fuels are water-diesel (W-D) emulsions and microemulsions. Numerous studies showed that combustion of W-D improves the efficiency of unmodified engines and also reduces the emission of harmful gases [11, 19]. The results of the research carried out with emulsified fuel confirmed that W-D can support the reduction of $\mathrm{NO}_{\mathrm{x}}$ and $\mathrm{PM}$ simultaneously. It was found that the water dispersed in diesel fuel supports the micro-explosion of the fuel droplets injected into the combustion chamber. Almost all authors agree that better performance and ecological benefits are caused mainly by the enhanced fuel atomization due the micro-explosion phenomena $[23,29]$. In this way, the quality of the fuel atomization process is accordingly higher. It should be pointed that so-called secondary atomization caused by the micro-explosion is affected by many factors, including the size of water particles dispersed in emulsion. The afore-mentioned problem was investigated by Marrone et al. [22]. In their work, the impact of the water droplet size dispersed in the fuel emulsion on the disruptive phenomenon (micro-explosion) was studied. The W-D emulsions containing the water particles in the diameter range of $2.1-4.5 \mu \mathrm{m}$ were investigated. Marrone concluded that only larger water particles can support the disruptive burning of the W-D emulsion. Similar results were reported by Mura et al. [24]. They confirmed that the most valuable water particle size dispersed in the W-D emulsion is $4.7 \mu \mathrm{m}$. Above this size, the microexplosion phenomenon is not so intensive. Additionally, Jeong et al. [18] investigated the impact of different water content dispersed in emulsion on the micro-explosion phenomenon. The authors suggested that the intensity of this phenomenon grows for the increasing the content of water percentage dispersed in the W-D emulsion. The factors affecting the usefulness of the W-D emulsion as a fuel for diesels were specified by Ithnin et al. $[14,15]$. The researchers concluded that the most important factors are the diameter and percentage of water particles dispersed in W-D emulsion, thermodynamical parameters such as temperature and pressure, as well as the kind and content of the surfactant used. They stated that also the condition of the engine operation as well as the kind of diesel engine should be taken into consideration.
It should be pointed that the water can be dispersed in a diesel fuel forming emulsion or microemulsion. On the basis of the literature data it can be stated that the W-D emulsion is not thermodynamically stable and easily separates even during short term storage. However, selected emulsions can be stable even for a few months [31]. It is also known that the stability of the W-D mixture is affected by properties of surfactants (emulsifiers) which are necessary for reducing the interfacial tension between water and oil (in this case - diesel fuel). On the basis of the literature data, it can be found that one of the most common chemicals considered as emulsifiers are Sorbitan oleate (CAS No.: 1338-43-8), Polyoxyethylene sorbitan oleate (CAS No.: 9005-57-1), Octyl Phenoxy polyethoxy ethanol (CAS No.: 9002-93-1), Polyoxyethylene sorbitan monolaurate (CAS No.: 9005-64-5) and Polyoxyethylene nonylphenyl ether (CAS No.: 68412-54-4) [12]. These surface active agents and other similar chemicals allow dispersing distilled water in diesel fuel. The stability of these emulsions is affected by the water/surfactant ratio as well as by temperature variations, density, viscosity and other factors [25]. During destabilization of the water-diesel emulsion, several processes may occur i.e. flocculation, coalescence, creaming or sedimentation. Flocculation is a process when dispersed water droplets create larger clusters. This is the first step leading to the emulsion coalescence and finally to the gravitational phase separation due to different densities of the water and oil phases [14, 15]. It should be pointed out that when the emulsion reaches the sedimentation stage, then the probability of malfunction as well as the risk of damages of the engine parts increases significantly. The destabilization phenomenon of the water-diesel fuel emulsion was tested in numerous studies. Ghannam et al. [7] investigated an emulsion containing $10 \%$ and $20 \%$ of water dispersed in diesel fuel with the $0.2 \%$ addition of surfactant. They stated that tested emulsion containing $10 \%$ of water remained stable even for 4 weeks. For a higher concentration of water dispersed in a diesel fuel, the stability of emulsion was adequately shorter. In the case of an emulsion containing more than $20 \%$ of water, the stability was reduced to 5 hours. Similar investigations were carried out by Rehan et al. [28]. However, researchers were focused on the selected factors influencing the stability of the water-biofuel emulsion. On the basis of the literature data, it can be stated that some surfactants 
allow dispersing water, forming a stable emulsion. Usually, it requires a higher amount of surfactants as well as cosurfactants. In this way, the fuel microemulsions containing up to about $10 \%$ by volume of water dispersed in diesel fuel can be formed with the addition of about $5-10 \%$ by mass of selective surfactants/cosurfactants. The size of the water micelles dispersed in the microemulsion is significantly lower compared with the emulsion. In detail, the size of water micelles in the microemulsion is lower than the wavelength of visible light i.e. in the range of 400-700 nm. For this reason, microemulsions are transparent and look similar to the standard diesel fuel, whereas emulsions usually appear white or milky.

As mentioned above, the W-D emulsions were commonly reported as effective and alternative fuels for diesel engines. Alahmer et al. [2, 3] tested the W-D emulsions containing up to $30 \%$ of water. In both cases the emission of nitrogen oxides was significantly lowered for the engine fuelled with the W-D emulsions in comparison with standard diesel fuel. Additionally, Yang et al. [31] confirmed that $\mathrm{NO}_{\mathrm{x}}$ emission is lowered when using the W-D emulsion due the presence of water bringing down the top temperature of the flame in the combustion chamber. It should be pointed out that higher temperature always stimulates the formation of $\mathrm{NO}_{\mathrm{x}}$. For this reason a reduction of the flame temperature lowers the $\mathrm{NO}_{\mathrm{x}}$ formation. $\mathrm{A}$ lot of researchers agree that the evaporation of the water injected into the combustion chamber absorbs the heat. In this way, the peak temperature during the W-D emulsion combustion process is accordingly reduced [21]. Farfaletti et al. [6] suggested that the heat sink phenomenon is responsible for lowering the burning gases temperature. For this reason, the emission of nitrogen oxides can be accordingly lowered. Jazair et al. [17] stated that the evaporation of water is an endothermic process associated with the water transition from the liquid phase to steam. In this case, the endothermic process carried out in the combustion chamber reduces the in-cylinder temperature affecting the lower emission of nitrogen oxides. Fahd et al. [5] investigated a W-D emulsion containing $10 \%$ water as a fuel for diesel engine. The authors evaluated the emissions and performance of the tested engine in wide range of its load and crankshaft rotational speed. On the basis of the results, they emphasized that the in-cylinder pressure during the combustion of the W-D emulsion and standard diesel fuel are comparable. They confirmed that the tested emulsion lowers the exhaust stream gases temperature and the nitrogen oxide emission is also reduced. Similar results were reported by Ghojel et al. [8]. These researchers tested a W-D emulsion containing 13\% water as a fuel for diesel engine. The necessary tests were carried out under stationary conditions for $150 \mathrm{Nm}$ obtained at $2200 \mathrm{rpm}$. During the research, a lower emission of unburned hydrocarbon as well as $\mathrm{NO}_{\mathrm{x}}$ was confirmed for the engine powered with the W-D emulsion. Moreover, Ithnin et al. [14] investigated the impact of a W-D emulsion containing up to $20 \%$ water on the performance and emission of the diesel engine operated in a wide range of load and constant speed of $3000 \mathrm{rpm}$. They highlighted lower emission of particulate matter and nitrogen oxides for all tested W-D emulsions. Moreover, they confirmed that the pressure variations recorded during the combustion process of all tested fuels were comparable. The experimental results reported by Yang et al. [32] once again confirmed that the W-D emulsions reduce the emission of nitrogen oxides significantly. During the tests, almost $31 \%$ reduction of $\mathrm{NO}_{\mathrm{x}}$ was achieved for an engine powered with the W-D emulsion containing up to $15 \%$ water, in comparison to the results obtained for standard diesel fuel. Similar reduction of nitrogen oxides was reported by Ithnin et al. [16]. The researchers investigated two different W-D emulsions containing $5 \%$ of water dispersed in diesel fuel. The first tested emulsion was formed without the necessary surfactant and the second was prepared with the addition of $0.2 \%$ of SPAN 80 . The research showed that the first W-D emulsion allows reducing not only $\mathrm{NO}_{\mathrm{x}}$ but also particulate matter by about $32 \%$ and $16 \%$, respectively, for an engine speed of $3000 \mathrm{rpm}$. Once again, Ithnin et al. [15] reported the results of an investigation on the W-D emulsion containing $2 \%$ of necessary surfactant and water dispersed in the diesel fuel in volume of 5, 10, 15 and $20 \%$. This time, the emission of $\mathrm{NO}_{\mathrm{x}}$ was reduced by $41 \%$, in comparison with the base diesel fuel. Similar results were reported by Yilmaz et al. [33]. They investigated a W-D emulsion containing 5\% and $10 \%$ of water dispersed in diesel fuel. The necessary tests were carried out for the engine operated at full load and moderate as well as higher speed of the engine crankshaft. The authors highlighted that the W-D emulsion containing $10 \%$ of water reduces the nitrogen oxides emission even by $11 \%$. Attia et al. [4] examined the impact of the emulsion structure 
on several parameters of engine operation. They confirmed that the emission of nitrogen oxides is lowered up to $25 \%$ for the emulsion containing larger water droplets. In this case, also smoke emissions as well as unburned hydrocarbons were reduced, even by $80 \%$ when the engine was fuelled with the W-D emulsion, in comparison with standard diesel oil. Henningsen [13] investigated a two-stroke engine powered with a W-D emulsion containing $25 \%$ water. He showed that the engine powered with the tested emulsion can generate even $30 \%$ lower emission of nitrogen oxides in comparison with diesel fuel. Ogunkoya et al. [27] tested the W-D emulsion containing $30 \%$ of water dispersed in diesel fuel. The necessary tests were carried out for a diesel engine at $2000 \mathrm{rpm}$ and three load conditions. The authors confirmed that the combustion of the W-D emulsion reduced the emission of nitrogen oxides significantly; however, larger emission of $\mathrm{CO}$ was also observed. Maiboom et al. [21] tested a high-speed direct injection (HSDI) diesel fuelled with a W-D emulsion with water/fuel ratio of $25.6 \%$. They confirmed that the utilisation of the tested W-D emulsion allowed achieving even 50\% reduction of $\mathrm{NO}_{\mathrm{X}}$, in comparison with the results obtained for standard fuel.

All the above-mentioned works confirm that water dispersed in diesel fuel has a positive influence on reducing the harmful gases produced by diesel engines. However, little is known about the impact of the W-D microemulsions on the performance and emissions from diesel engines. Some reports confirm that microemulsions can also reduce the harmful emissions from the engine [1]. However, other authors reported an increase in the $\mathrm{CO}$ and NOx emission, in comparison with diesel fuel [26]. The examples of these opposite reports were the motivation for own empirical tests carried out with the AVL research engine powered with the microemulsion containing up to $7 \%$ by volume of distillate water dispersed in standard diesel fuel. The paper is focused on the analysis of the $\mathrm{NO}_{2}, \mathrm{NO}$ and $\mathrm{NO}_{\mathrm{X}}$ emissions, which are considered as a one of the most important harmful gases from diesel engines.

\section{MATERIALS AND METHODS}

In this study the AVL 5402 series Common Rail diesel research engine was used. It is a wellknown unit designed for professional scientific tests. In detail, the engine consists of a $0.51 \mathrm{~L}$ single cylinder equipped with 4 valves and direct fuel injection system produced by $\mathrm{BOSCH}$ Co. The basic specifications of the AVL engine are shown in Table 1. The test setup used in this research was built by the AVL Co. for the Kazimierz Pulaski University of Technology and Humanities in Radom. The schematic diagram of this test setup is shown in Figure 1.

As it can be seen from Figure 1, the power generated by the engine was absorbed by eddy current dynamometer working under supervision of an Engine\&Dyno control system. The test setup was equipped with the AVL Sesam i60 FT multi-component exhaust measurement system.

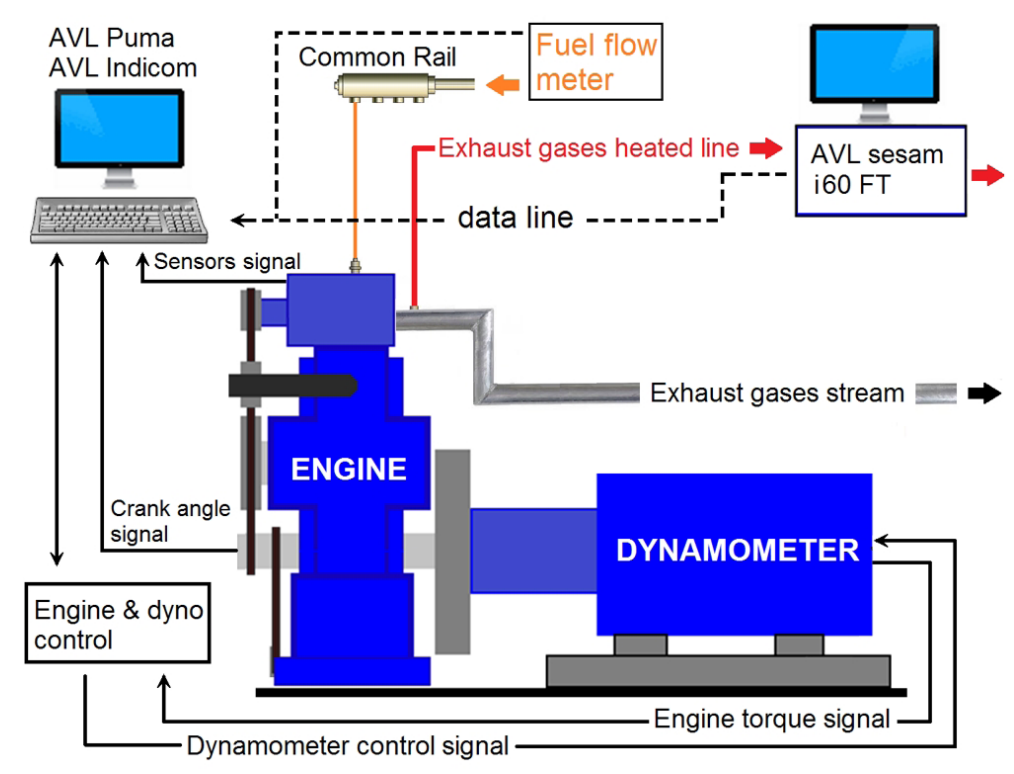

Fig. 1. Schematic diagram of the test setup 
Table 1. Selected specification of the AVL 5402 engine

\begin{tabular}{|l|l|}
\hline \multicolumn{1}{|c|}{ Parameter } & \multicolumn{1}{c|}{ Value } \\
\hline Engine type & 4-stroke, single cylinder \\
\hline Engine cooling system & liquid \\
\hline Fuel injection type & Common Rail, BOSCH CP4.1 \\
\hline Engine test stand controller & $\begin{array}{l}\text { AVL-RPEMS and ETK7 } \\
\text { BOSCH }\end{array}$ \\
\hline $\begin{array}{l}\text { Maximum pressure of fuel } \\
\text { injection }\end{array}$ & $180 \mathrm{MPa}$ \\
\hline Maximum engine power & $6.25 \mathrm{~kW}$ at 4200 rpm \\
\hline Compression ratio & $17.5: 1$ \\
\hline Valves per cylinder & 2 inlet, 2 exhaust \\
\hline Displacement & $511 \mathrm{~cm}^{3}$ \\
\hline
\end{tabular}

Selected specification of this system is listed in Table 2.

The AVL SESAM i60 FT contains three main devices, i.e.: flame ionization detector (FID), infrared detector (IRD) and paramagnetic detector (PMD). The FID analyzer was used for the measurements of the total unburned hydrocarbon (THC) concentration in the exhaust stream gases flow. $\mathrm{CO}$ and $\mathrm{CO}_{2}$, as well as many other infrared active chemical compounds like NO and $\mathrm{NO}_{2}$ were measured using a Fourier Transform Infrared spectroscopy (FTIR). The oxygen concentration in the exhaust stream gas was analyzed by the PMD. It should be pointed that the AVL SESAM i60 FT exhaust gas measurement system allows detecting over 20 gas components through the analysis of an infrared broadband spectrum. The system updates the results at the frequency of $1 \mathrm{~Hz}$. According to the producer's data, the spectrometer operates with spectral resolution of $0.5 \mathrm{~cm}^{-1}$. The necessary measurements began when the stationary condition of the engine work was achieved. For this reason, the engine coolant and oil temperature was also controlled. Once these parameters became steady, the emissions were recorded by the AVL Puma and AVL

Table 2. Selected specification of the AVL SESAM i60 FT emission analyser

\begin{tabular}{|l|c|c|}
\hline \multicolumn{1}{|c|}{ Gas component } & MDC* (ppm) & Range (ppm) \\
\hline Dinitrogen monoxide $\mathrm{N}_{2} \mathrm{O}$ & 1.0 & $0-1000$ \\
\hline Ammonia $\mathrm{NH}_{3}$ & 0.5 & $0-1000$ \\
\hline Nitrogen monoxide $\mathrm{NO}$ & 2.5 & $0-10000$ \\
\hline Nitrogen dioxide $\mathrm{NO}_{2}$ & 1.0 & $0-1000$ \\
\hline
\end{tabular}

MDC* - Minimal Detectable Concentration is the detection limit of involved gas component, defined assuming two times the standard deviation
Indicom system. As mentioned above, the engine tested in this research used the CR injection system controlled by programmable Engine Control Unit (ECU). The necessary tests were carried out under the conditions of low, moderate and higher load of the engine work. The engine operated with 1200, 2200 and $3200 \mathrm{rpm}$ of the crankshaft. At each speed, the engine operated under three loads i.e. break mean effective pressure (BMEP) was set to $1.7,3.4$ and 5.1 bar. In this way, a matrix of nine measurement points was established. The settings of the pilot and main fuel injection timing were the same for all fuels tested in the specific measurement point. The exhaust gases recirculation (EGR) system and turbocharging system were not used in this study.

It should be pointed that in this study the empirical studies were focused on the investigation of the water content dispersed in diesel fuel on the nitrogen oxides emission characteristics of the AVL engine. Diesel fuel (DF) and two fuel microemulsions containing 3.5 and $7.0 \%$ by volume of distilled water were tested. These tested microemulsions are coded as follows: M1 and M2, respectively. Distillate water was dispersed in diesel fuel using surface active agents: Span20 and Crillet-6. All tested fuels had the same 6\% by mass content of the afore-mentioned surfactants. Both tested microemulsions were formed at a temperature of $40^{\circ} \mathrm{C}$. Then, the Zetasizer Nano analyzer (made by Malvern Co) was used to measure the size of water micelles dispersed in diesel fuel. These tests were repeated three times. The results confirmed that the average size of micelles is close to $18-20 \mathrm{~nm}$. For all tested fuels the kinematic viscosity, cold filter plugging point, density, flash point and cooper strip corrosion tests were performed. The details of the tested physicochemical properties of DF, M1 and M2 are listed in Table 3.

On the basis of the data shown in Table 3, it can be stated that the values of cold filter plugging point of M1 and M2 were comparable to DF. However, the viscosity of M1 and M2 increased significantly, in comparison with the base diesel fuel. It can deteriorate the fuel atomization process in the combustion chamber. The water dispersed in diesel fuel increased the flash point value. Especially the flash point of M2 increased significantly compared with DF. For this reason, the M2 mixture seems to be safer and it can be recommended for special applications such as combat vehicles. 
Table 3. Selected physicochemical properties of tested fuels

\begin{tabular}{|l|c|c|c|c|}
\hline \multirow{2}{*}{ Property } & \multirow{2}{*}{ Unit } & \multicolumn{3}{c|}{ Value } \\
\cline { 3 - 5 } & & $\mathrm{DF}$ & $\mathrm{M} 1$ & $\mathrm{M} 2$ \\
\hline Density at $15^{\circ} \mathrm{C}$ & $\mathrm{kg} / \mathrm{m}^{3}$ & 837 & 851 & 855 \\
\hline Water content by volume & $\%$ & 0 & 3.5 & 7.0 \\
\hline Crillet-6/Span-20 content by mass & $\%$ & 6.0 & 6.0 & 6.0 \\
\hline Kinematic viscosity at $40^{\circ} \mathrm{C}$ & $\mathrm{mm}^{2} / \mathrm{s}$ & 2.82 & 3.45 & 3.96 \\
\hline Cold filter plugging point & ${ }^{\circ} \mathrm{C}$ & -15 & -13 & -11 \\
\hline Flash point & ${ }^{\circ} \mathrm{C}$ & 66 & 80 & 106 \\
\hline Copper strip corrosion & - & $1 \mathrm{a}$ & $1 \mathrm{~b}$ & $1 \mathrm{~b}$ \\
\hline
\end{tabular}

\section{RESULTS AND DISCUSSION}

$\mathrm{NO}_{2}$ as well as $\mathrm{NO}$ are the main components of nitrogen oxides referred to as $\mathrm{NO}_{\mathrm{x}}$. Its emission has a negative impact on the human health. In particular $\mathrm{NO}_{\mathrm{x}}$ promote the swelling of throat bronchitis and lung inflammation. Moreover, the exposure to $\mathrm{NO}_{\mathrm{X}}$ contributes to lowered oxygen saturation of the blood system and promotes asthma attacks.

$\mathrm{NO}_{\mathrm{x}}$ are formed during the combustion process, mainly in the front of the flame. The fundamental principle of the $\mathrm{NO}_{\mathrm{x}}$ formation is strictly related with the in-cylinder temperature variation i.e. higher emission of $\mathrm{NO}_{\mathrm{x}}$ correlates with higher temperature of the combustion process. As mentioned above, a lot of studies suggest that the problem of the $\mathrm{NO}_{\mathrm{x}}$ emission can be reduced by using the W-D emulsion as a fuel for CI engines. During fuel combustion, the water micelles evaporate and this endothermic process absorbs the latent and sensible heat. For this reason, the incylinder temperature is lowered, as well as lower emission of $\mathrm{NO}$ and $\mathrm{NO}_{2}$ is expected. It is mostly confirmed in this research. As shown in Figure 2, the maximum emission of NO does not exceed a value of $1 \mathrm{~g} / \mathrm{kWh}$ for all tested fuels.

It is also clear that the variation of the engine load, i.e. BMEP value, slightly lowers the NO emission. The water dispersed in diesel fuel does not have an important influence on the emission of NO. The formation of NO during the combustion process can be described by the temperaturedependent chemical reactions. The major factor influencing the NO formation is the oxygen excess in the combustion chamber and temperature. For higher loads, the air/fuel ratio is adequately reduced. It means that the oxygen concentration in combustion chamber is also lower. For this reason, a lower number of oxygen atoms can react with a nitrogen molecule, forming $\mathrm{NO}$ and $\mathrm{N}$ :

$$
\mathrm{O}+\mathrm{N}_{2} \rightarrow \mathrm{NO}+\mathrm{N}
$$

Then, a nitrogen atom can react with a oxygen molecule giving NO:

$$
\mathrm{N}+\mathrm{O}_{2} \rightarrow \mathrm{NO}+\mathrm{O}
$$

The above-mentioned process is commonly known as the Zeldovich's mechanism. The rate of NO formation is maximized by higher temperature and increased oxygen concentration. At the temperature greater than about $1500{ }^{\circ} \mathrm{C}$, a triple bond in $\mathrm{N}_{2}$ molecule breaks. It means that the $\mathrm{NO}$ formation is affected by the nitrogen molecule dissociation inside the combustion chamber. At a lower temperature, the formation of prompt NO occurs. Under such conditions, the hydrocarbon radicals easily react with molecular nitrogen $\mathrm{N}_{2}$ forming hydrogen cyanide $\mathrm{HCN}$ (eq. 3) and other radicals. Then, these chemicals easily oxidize in the flame forming NO:

$$
\mathrm{CH}_{2}+\mathrm{N}_{2} \rightarrow \mathrm{HCN}+\mathrm{NH}
$$

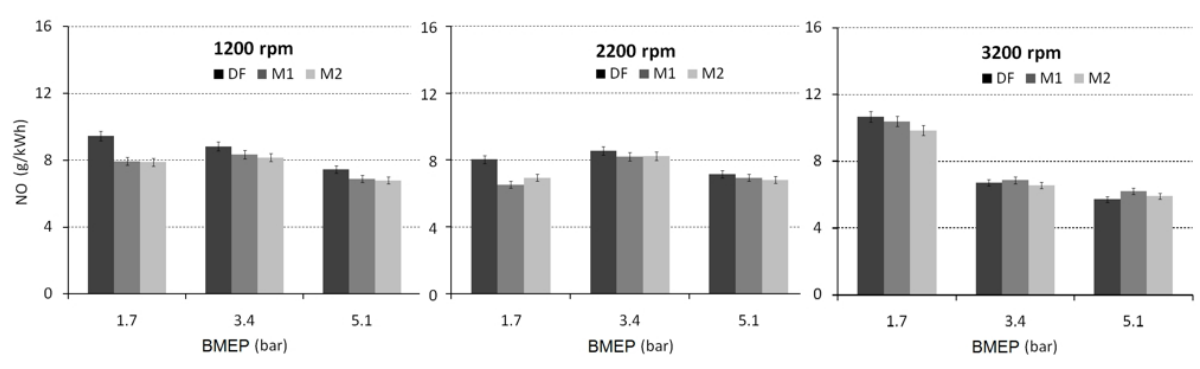

Fig. 2. NO emission from the AVL engine fuelled with DF and microemulsions 


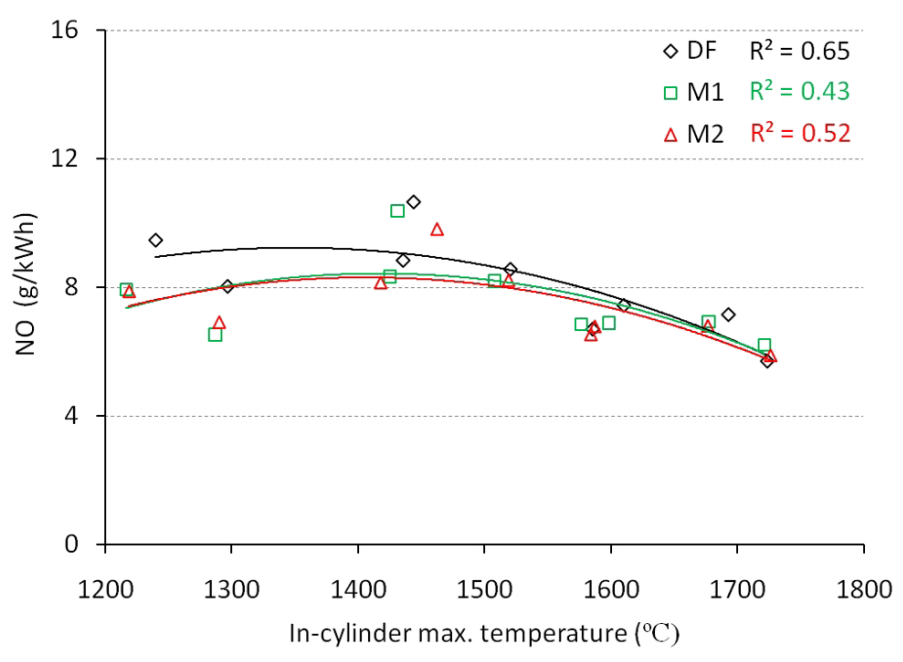

Fig. 3. An impact of a peak combustion temperature on the NO emission from the diesel engine fuelled with DF and microemulsions

All the above-mentioned mechanisms are examples of complex processes of $\mathrm{NO}_{\mathrm{X}}$ formation inside the combustion chamber. However, it should be pointed out that all emissions from the AVL engine were sampled from the exhaust stream in a heated line to prevent gas condensation. In Figure 3 the relationship between the NO emissions sampled from the exhaust stream versus in-cylinder peak temperature is expressed.

Figure 3 shows that the NO emission was not affected by the variation of the in-cylinder maximum temperature. Additionally, the kind of the fuel tested in this study had a minor effect on the $\mathrm{NO}$ emission. However, it can be stated that below $1400{ }^{\circ} \mathrm{C}$, the emission of $\mathrm{NO}$ was reduced up to $10 \%$ compared with DF. In this research, the $\mathrm{NO}_{2}$ emission was also measured in the exhaust stream gases. The results are shown in Figure 4. As it can be seen, the emission of $\mathrm{NO}_{2}$ from the engine was significantly lower compared with NO for all measurement conditions.

$\mathrm{NO}_{2}$ are formed during the oxidation of $\mathrm{NO}$ by the oxygen present in air. The process is more efficient in the excess of oxygen available in the combustion chamber. An increase of the rotational speed of the engine crankshaft always decreases the filling of the combustion chamber with fresh air. In this way, the oxygen content is accordingly reduced. For this reason, the lowest $\mathrm{NO}_{2}$ emission was detected at $3200 \mathrm{rpm}$. At low speed ,i.e. $1200 \mathrm{rpm}$, the emission of $\mathrm{NO}_{2}$ is the highest because the efficiency of combustion chamber filling is the best. It contributes to higher concentration of oxygen in the combustion chamber and promotes the oxidation of NO. The described mechanism is also related with the engine load dependent on the fuel dose inject into the combustion chamber. Achieving higher BMEP requires more fuel injected into the combustion chamber. It has an impact on lowering the oxygen excess available for the NO oxidation. For this reason, the $\mathrm{NO}_{2}$ formation is reduced when the BMEP value increase. Taking into account the data presented in Fig. 4, it can be stated that the water dispersed in diesel fuel can support the reduction of $\mathrm{NO}_{2}$. Mostly, the reduction of $\mathrm{NO}_{2}$ is minor or even increases, such as in the case of the engine operated at $2200 \mathrm{rpm}$ and 1.7 of BMEP. However, even these divergent data can suggest that water has a potential for the reduction of $\mathrm{NO}_{2}$. Such statement is additionally confirmed in Figure 5.

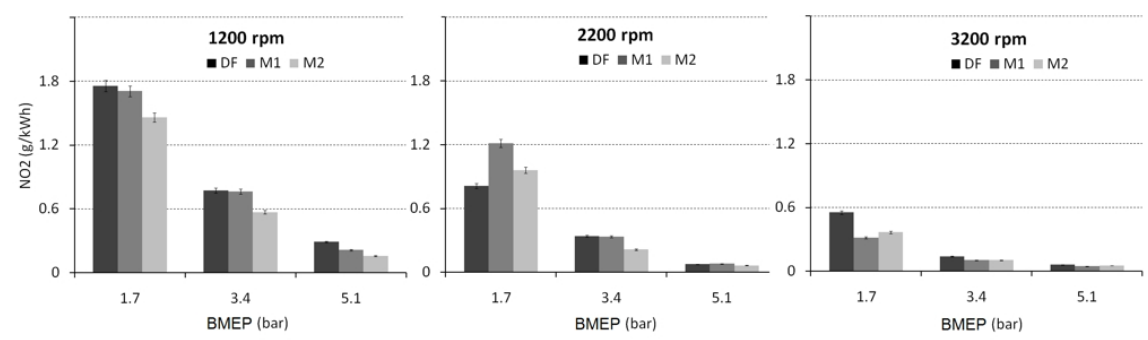

Fig. 4. $\mathrm{NO}_{2}$ emission from the engine fuelled with $\mathrm{DF}$ and microemulsions 
The analysis of Figure 5 confirms that the addition of water to diesel fuel allows reducing the emission $\mathrm{NO}_{2}$ approx. by $10 \%$, compared with DF. Moreover it is clear that the $\mathrm{NO}_{2}$ formation i.e. oxidation of $\mathrm{NO}$ is the most efficient for low in-cylinder temperatures. An increase of these temperatures has an impact on the low value of the $\mathrm{NO}_{2}$ emission. However, in such case, the $\mathrm{NO}$ emission is still high for all tested fuels.

Taking into account the emission of all nitrogen oxides (Fig. 6) detectable by the AVL SESAM i60 FT, it can be stated that increasing BMEP (i.e. higher engine load) enables to slightly reduce the $\mathrm{NO}_{\mathrm{x}}$ emission. The possible benefits depend on many factors; however, BMEP is the most important is one. According to the authors, the kind of fuel combusted in the engine does not have a significant effect on the $\mathrm{NO}_{\mathrm{x}}$ formation.

The combustion process of any fuel in air will always promote the formation of nitrogen oxides. According to our results summarized in Figure 7, it can be stated that the water available in diesel fuel supports the reduction of the $\mathrm{NO}_{\mathrm{x}}$ formation to a limited extent.
However, the influence of the water content in diesel fuel on the $\mathrm{NO}_{\mathrm{X}}$ emission reduces with an increase of the in-cylinder temperature. On the basis of our experiences, it can be stated that the combustion process carried out in compressed air will always promote the formation of $\mathrm{NO}_{\mathrm{x}}$. The addition of water to diesel fuel can slightly reduce the $\mathrm{NO}_{\mathrm{x}}$ emission, but it will not solve environmental challenges.

\section{CONCLUSIONS}

In this work, the AVL research engine equipped with professional the AVL SESAM i60 FT exhaust gas measurement system was used to assess the impact of the water content dispersed in diesel fuel on the emission of nitrogen oxides. In the research, 3.5 and $7 \%$ by volume of distilled water was blended with diesel fuel. In this way two microemulsions were prepared and tested in the engine. The necessary tests were carried out for low, moderate and high loads as well as for low, moderate and high rotational speeds

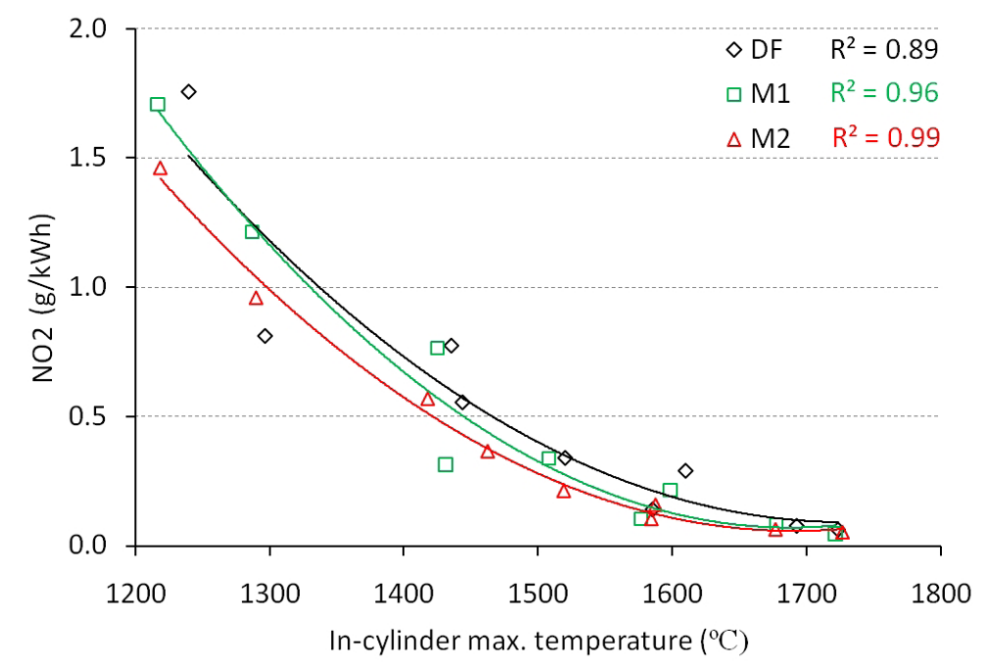

Fig. 5. An impact of a peak combustion temperature on the $\mathrm{NO}_{2}$ emission from the diesel engine fuelled with DF and microemulsions

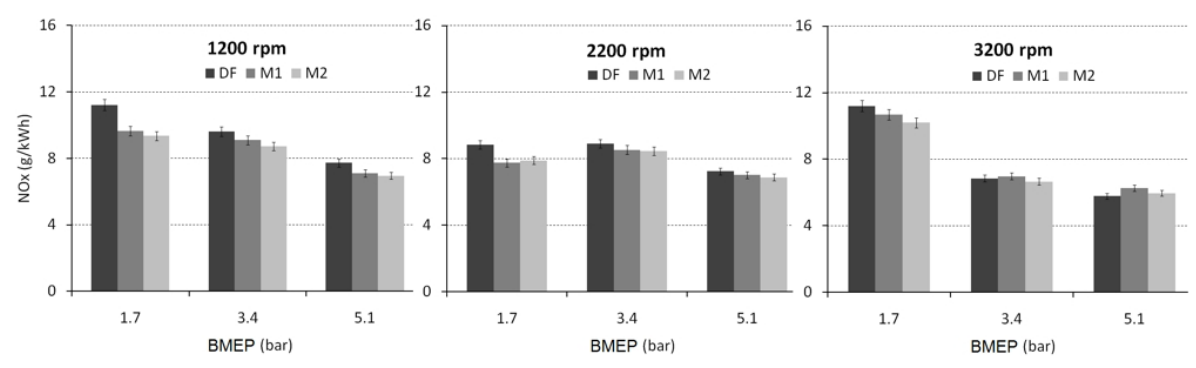

Fig. 6. $\mathrm{NO}_{\mathrm{x}}$ emission from the engine fuelled with $\mathrm{DF}$ and microemulsions 


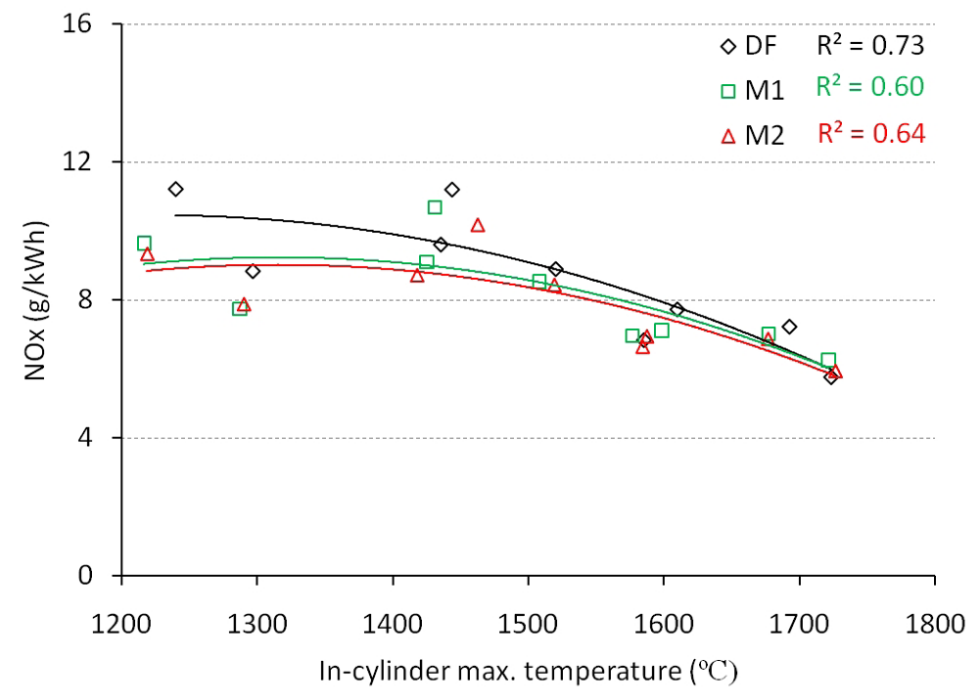

Fig. 7. An impact of a peak combustion temperature on the $\mathrm{NO}_{\mathrm{X}}$ emission from the diesel engine fuelled with DF and microemulsions

of the engine crankshaft. Such settings allowed performing the necessary engine tests in a wide range of the possible work conditions. On the basis of the results obtained during the performed research, it was found that a microemulsion containing up to $7 \%(\mathrm{v} / \mathrm{v})$ of water has a minor effect on the reduction of $\mathrm{NO}_{\mathrm{x}}$. It can suggest that the content of water in both tested microemulsions was not enough for the reduction of temperature caused by the fuel evaporation in the combustion chamber. For this reason, further tests are recommended for the microemulsions containing more than $10 \%$ of water. Moreover, additional studies focused on the micro-explosions of microemulsion should be performed due the lack of knowledge in this manner.

\section{REFERENCES}

1. Abrar I., Bhaskarwar A. Formulation and Extension of Diesel-Based Microemulsion Fuels for Compression Ignition Engine. INAE Letters. 3, 2018, 33-39.

2. Alahmer A. Influence of using emulsified diesel fuel on the performance and pollutants emitted from diesel engine. Energy Conversion and Management. 73, 2013, 361-369.

3. Alahmer A., Yamin J., Sakhrieh A., Hamdan M.A. Engine performance using emulsified diesel fuel. Energy Conversion and Management. 51(8), 2010, 1708-1713.

4. Attia A.M., Kulchitskiy A. Influence of the structure of water-in-fuel emulsion on diesel engine performance. Fuel. 116, 2014, 703-708.
5. Fahd M.E.A., Wenming Y., Lee P.S., Chou S.K., Yap C.R. Experimental investigation of the performance and emission characteristics of direct injection diesel engine by water emulsion diesel under varying engine load condition. Applied Energy. 102, 2013, 1042-1049.

6. Farfaletti A., Astorga C., Martini G., Manfredi U., Mueller A., Rey M., De Santi G., Krasenbrink A., Larsen B.R. Effect of water/fuel emulsions and a cerium-based combustion improver additive on HD and LD diesel exhaust emissions. Environmental science \& technology. 39(19), 2005, 6792-6799.

7. Ghannam M., Selim M. Stability behavior of water-in-diesel fuel emulsion. Petroleum Science and Technology. 27(4), 2009, 396-411.

8. Ghojel J., Honnery D., Al-Khaleefi K. Performance, emissions and heat release characteristics of direct injection diesel engine operating on diesel oil emulsion. Applied Thermal Engineering. 2006, 26(17-18), 2006, 2132-2141.

9. Górski K., Smigins R. Selected physicochemical properties of diethyl ether/rapeseed oil blends and their impact on diesel engine smoke opacity. Energy Fuels. 32(2), 2018, 1796-1803.

10. Górski K., Przedlacki M. Evolution of the influence of Diethy Ether (DEE) addition on selected physicochemical properties of diesel oil and ignition delay period. Energy and Fuels. 28(4), 2014, 2608-2616.

11. Hagos F.Y., Aziz A.R.A., Tan I.M. Water-in-diesel emulsion and its micro-explosion phenomenon-review. IEEE 3rd International Conference on Communication Software and Networks. 2011.

12. Hasannuddin A., Yahya W.J., Sarah Y., Ithnin A.M. 2016. Durability studies of single cylinder diesel engine running on emulsion fuel. Energy. 94, 2016, $557-568$. 
13. Henningsen $\mathrm{S}$. Influence of the fuel injection equipment on NOx emissions and particulates on a large heavy-duty two-stroke diesel engine operating on water-in-fuel emulsion. SAE transactions. 1994, 1855-1871.

14. Ithnin A.M., Ahmand M.A., Abu Bakar M.A., Rajoo S., Yahya W.J. Combustion performance and emission analysis of diesel engine fuelled with water-in-diesel emulsion fuel made from low-grade diesel fuel. Energy Conversion and Management. 90, 2015, 375-382.

15. Ithnin A.M., Noge H., Abdul Kadir H., Jazair W. An overview of utilizing water-in-diesel emulsion fuel in diesel engine and its potential research study. Journal of the Energy Institute. 87(4), 2014, 273-288.

16. Ithnin A.M., Yahya W.J., Ahmad M.A., Ramlan N.A., Kadir H.A., Che Sidik N.A., Koga T. Emulsifier-free Water-in-Diesel emulsion fuel: Its stability behaviour, engine performance and exhaust emission. Fuel. 215, 2018, 454-462.

17. Jazair W., Kubo S., Takayasu M., Yatsufusa T. Performance and emission characteristics of a diesel engine fueled by rapeseed oil bio-fuel. Jurnal Mekanikal. 2011, 33(2).

18. Jeong I., Lee K. Auto-ignition and micro-explosion behaviors of droplet arrays of water-in-fuel emulsion. International Journal of Automotive Technology. Vol. 9(6), 2008, 735-740.

19. Lif A., Holmberg K. Water-in-diesel emulsions and related systems. Advances in colloid and interface science. 123, 2006, 231-239.

20. Longwic R., Sander P., Zdziennicka A., Szymczyk K., Jańczuk B. Combustion Process of Canola Oil and n-Hexane Mixtures in Dynamic Diesel Engine Operating Conditions. Applied Sciences. 10(1), 2020.

21. Maiboom A., Tauzia X. NOx and PM emissions reduction on an automotive HSDI Diesel engine with water-in-diesel emulsion and EGR: An experimental study. Fuel. 90(11), 2011, 3179-3192.

22. Marrone N.J., Kennedy I.M., Dryer F.L. Internal phase size effects on combustion of emulsions. Combustion science and technology. 33(5-6), 1983, 299-307.

23. Mondal P.K., Mandal B.K. A comprehensive review on the feasibility of using water emulsified diesel as a CI engine fuel. Fuel. 237, 2019, 937-960.
24. Mura E., Josset C., Loubar K., Huchet G. Effect of Dispersed Water Droplet Size in Microexplosion Phenomenon Forwater in Oil Emulsion. Atomization and sprays. 20(9), 2010, 791-799.

25. Nadeem M., Rangkuti C., Anuar K., Haq M.R.U., Tan I.B.,Shah S.S. Diesel engine performance and emission evaluation using emulsified fuels stabilized by conventional and gemini surfactants. Fuel. 85(14-15), 2006, 2111-2119.

26. Neto A.A.D., Fernandes M. R., Neto E.L.B., Dantas T.N.C., Moura M.C.P.A. Alternative fuels composed by blends of nonionic surfactant with diesel and water: engine performance and emissions. Brazilian Journal of Chemical Engineering. 28(3), 2011.

27. Ogunkoya D., Li S., Rojas O.J., Fang T. Performance, combustion, and emissions in a diesel engine operated with fuel-in-water emulsions based on lignin. Applied energy. 154, 2015, 851-861.

28. Reham S., Masjuki H.H., Kalam M.A., Shancita I., Rizwanul Fattah I.M., Ruhul A.M. Study on stability, fuel properties, engine combustion, performance and emission characteristics of biofuel emulsion. Renewable and Sustainable Energy Reviews. 52, 2015, 1566-1579.

29. Sheng H.-z., Chen L., Wu C.-k. The droplet group micro-explosions in $\mathrm{W} / \mathrm{O}$ diesel fuel emulsion sprays. SAE transactions. 1995, 1534-1542.

30. Venu H., Madhavan V. Influence if diethyl ether (DEE) addition in ethanol-biodiesel-diesel (EBD) and methanol-biodiesel-diesel (MBD) blends in a diesel engine. Fuel. 189, 2016, 377-390.

31. Yang W., An H., Chou S.K., Jon Ch.K. Impact of emulsion fuel with nano-organic additives on the performance of diesel engine. Applied energy. 112, 2013,1206-1212.

32. Yang W., An H., Chou S.K., Vedharaji S., Vallinagam R., Balaji M., Mohammad F.E.A., Chua K.J.E. Emulsion fuel with novel nano-organic additives for diesel engine application. Fuel. 104, 2013, 726-731.

33. Yilmaz E., Solmaz H., Polat S., AhmetUyumaz A., Şahin F., Salman M.S. Preparation of diesel emulsion using auxiliary emulsifier mono ethylene glycol and utilization in a turbocharged diesel engine. Energy Conversion and Management. 86, 2014, 973-980. 